\section{Influence of Silicon on Drought and Shade Tolerance of St. Augustinegrass}

\author{
Laurie E. Trenholm ${ }^{1}$, \\ Lawrence E. Datnoff ${ }^{2}$, and \\ Russell T. Nagata ${ }^{2}$
}

ADDITIONAL INDEX WORDs. abiotic stresses, multispectral reflectance, nitrogen, visual quality

Summary. The objectives of these studies were to evaluate the effects of silicon on drought and shade tolerance of st. augustinegrass (Stenotaphrum secundatum). Studies were conducted during 2001 in a glasshouse at the University of Florida Turfgrass Research Envirotron in Gainesville. For both drought and shade evaluations, calcium silicate slag $\left(\mathrm{CaSiO}_{3}\right)$ was pre-incorporated into pots with commercial potting soil at the rate of $3.36 \mathrm{~kg} \cdot \mathrm{ha}^{-1}(0.069$ $\left.\mathrm{lb} / 1000 \mathrm{ft}^{2}\right)$. 'FX-10' and 'FHSA115 ' st. augustinegrass were planted into $15.2-\mathrm{cm}$-diameter $\times 30.5-\mathrm{cm}$ deep $(6 \times 12$ inches $)$ plastic pots for the drought study and subjected to minimal irrigation. Under severe drought stress, silicon-amended plants had better responses than non-amended plants. Little improvement was seen under moderate drought stress. 'Floratam' and genotype 1997-6 were placed under full sunlight or $\mathbf{5 0 \%}$ to $70 \%$ shade. There was no benefit from use of silicon under shaded conditions. These findings suggest that silicon might provide improved tolerance to st. augustinegrass under severe drought stress.

S ilicon ( $\mathrm{Si}$ ) is presumably not essential for plant growth and development and is therefore not considered a true nutrient element (Epstein, 1994, 1999). However, soluble Si has enhanced the growth and development of several plant species (Datnoff et al., 2001), including creeping bentgrass (Agrostrispalustris)

${ }^{1}$ Environmental Horticulture Department, University of Florida, PO Box 110670, Gainesville, FL 32611. To whom reprint requests should be addressed; e-mail address: ltrenholm@ifas.ufl.edu

${ }^{2}$ University of Florida, Everglades Research and Education Center, 3200 East Palm Beach Rd., Belle Glade, FL 33430.
(Gussack et al., 1998), strawberry (Fragaria $\times$ ananassa) (Wang and Galletta, 1998), rice (Oryza sativa) (Savant et al., 1997), and sugarcane (Saccharum officinarum) (Savant et al., 1999). Silicon is actively absorbed through the roots as monosilicic acid $\left(\mathrm{SiOH}_{4}\right)$ and is then moved passively through the plant's transpiration stream. It is deposited in epidermal cells as silicate crystals as a silicon-cuticle double layer. This deposition forms a barrier that is believed to reduce water loss through the cuticles, resulting in greater turgor potential. This barrier has also been suggested to inhibit entrance of disease organisms into the plant (Belanger et. al., 1995).

Because of the characteristics of Si uptake and deposition in plants, there is increased interest in use of $S i$ to reduce effects of abiotic and biotic plant stress in a number of cultivated crops, including turfgrass. Wear injury of seashore paspalum (Paspalum vaginatum) was reduced by $20 \%$ with application of potassium silicate (Trenholm et al., 2001). Brecht (2004) noted less disease incidence in 'Floratam' st. augustinegrass that had been treated with calcium silicate. Application of $\mathrm{Si}$ at 24.41 and $48.82 \mathrm{~kg} \cdot \mathrm{ha}^{-1}(0.5$ and $1.0 \mathrm{lb} / 1000$ $\left.\mathrm{ft}^{2}\right)$ reduced severity of dollar spot (Sclerotinia homeocarpa) and brown patch (Rhizoctania solani) in creeping bentgrass (North Carolina State Univ., 1997). Creeping bentgrass 'Penncross' increased dry weight in response to $\mathrm{Si}$ application at 50 or $100 \mathrm{mg} \cdot \mathrm{L}^{-1}(\mathrm{ppm})$ Si (Gussack et al., 1998).

Effects of $\mathrm{Si}$ on turfgrass tolerance to other environmental stresses have not been investigated. Due to the deposition characteristics of $\mathrm{Si}$ in the leaf blade, Si may increase drought tolerance of turf. Conservation of water in the landscape and turfgrass water use are some of the major issues facing the turfgrass industry.

In addition, $\mathrm{Si}$ deposition may enhance photosynthetic light capture in leaf blades, possibly increasing turf growth and quality under reduced light conditions. Light is another factor that frequently limits turfgrass use and performance in urban landscapes, and a way of enhancing shade tolerance would be beneficial for turfgrass in the landscape.

The objectives of these experiments were to investigate the influence of $\mathrm{Si}$ on drought and shade tolerance of st. augustinegrass. 


\section{Materials and methods}

For drought tolerance evaluations, st. augustinegrass cultivar FX10 and the experimental genotype 'FHSA-115' were established in 15.2$\mathrm{cm}$-diameter $\times 30.5-\mathrm{cm}$-deep plastic pots in a glasshouse at the University of Florida Turfgrass Research Envirotron in Gainesville. Eight pots of each cultivar were established on 20 Dec. 2000. Substrate used was a $1: 1(\mathrm{v}: \mathrm{v})$ mixture of Fafard \#2 mix (Conrad Fafard, Agawam, Mass.) and coarse sand. Calcium silicate slag (Calcium Silicate Corp., Columbia, Tenn.) was pre-incorporated into half of the pots prior to planting at $3.36 \mathrm{~kg} \cdot \mathrm{ha}^{-1}$. Grasses were allowed to establish until 2 Feb. 2001, when deficit irrigation treatments were initiated. The first trial of this study was terminated on 26 Apr. 2001. The study was repeated from 14 June until 19 July 2001 with the same experimental details. Grasses were maintained throughout both trial periods with minimal irrigation as needed to keep grass alive but under severe drought stress, as observed by leaf folding. Volumes of water applied over the course of the experiment are listed in Table 1. Fertilizer was applied

Table 1. Irrigation water volumes and application dates to two st. augustinegrass cultivars ('FX-10' and 'FHSA115') during drought stress experiments in a greenhouse. Water was applied in quantities sufficient to keep the treatments from dying without promoting recovery.

\begin{tabular}{lc}
\hline Date & Trrigation applied $(\mathrm{mL})^{\mathrm{z}}$ \\
\hline 2 Feb. & Drought initiated \\
7 Feb. & 200 \\
9 Feb. & 500 \\
13 Feb. & 300 \\
23 Feb. & 300 \\
27 Feb. & 300 \\
2 Mar. & 300 \\
5 Mar. & 300 \\
9 Mar. & 300 \\
14 Mar. & 300 \\
27 Mar. & 200 \\
30 Mar. & 300 \\
12 Apr. & 300 \\
\multicolumn{2}{c}{ Trial 2 (June-July 2002) } \\
14 June & Drought initiated \\
25 June & 300 \\
2 July & 300 \\
9 July & 500 \\
10 July & 300 \\
\hline 1 &
\end{tabular}

${ }^{\mathrm{z}} 1 \mathrm{~mL}=0.034 \mathrm{fl} \mathrm{oz}$. monthly as a modified Beckman's solution to supply $12.206 \mathrm{~kg} \cdot \mathrm{ha}^{-1}(0.25$ $\left.\mathrm{lb} / 1000 \mathrm{ft}^{2}\right)$ of $\mathrm{N}$ with each application. Grasses were mowed by hand to a height of $6.35 \mathrm{~cm}$ (2.5 inches) every other week.

Visual turf quality, color, density, leaf folding, and leaf firing were evaluated, results of which were averaged monthly. Quality, color, and density were rated on a scale from 1 to 9 , where $1=$ dead grass and $9=$ best possible grass. Leaf folding was a visual estimate of the number of leaf blades per pot that had at least $50 \%$ of an individual blade folded. Leaf firing was a visual estimate of number of scorched leaf blade tips. In July, due to severe drought stress in all pots, a final rating of percent survival was taken, based on whether or not the plants showed any signs of regrowth from injury when irrigation was resumed.

Reflectance measurements were taken with a hand-held Cropscan multispectral model MSRI6 radiometer (Cropscan, Fargo, N.D.) fitted with filter wavelengths to measure reflectance at $450,550,660,694,710$, 760,810 , and $930 \mathrm{~nm}$. In addition, the following growth and stress indices were evaluated:

- NDVI (normalized difference vegetation index) growth index computed as $\mathrm{R}_{930}-\mathrm{R}_{660} / \mathrm{R}_{930}+\mathrm{R}_{660}$. Best $=$ highest value.

- IR/R (leaf area index) growth index computed as $\mathrm{R}_{930} / \mathrm{R}_{600}$. Best $=$ highest value.

- Stress $\mathrm{l}$ index computed as $\mathrm{R}_{710} /$ $\mathrm{R}_{760}$. Best $=$ lowest value.

- Stress 2 index computed as $\mathrm{R}_{71} 0 /$ $\mathrm{R}_{810}$. Best $=$ lowest value.

The indices NDVI and IR/R have shown strong correlations with turf visual qualitative characteristics (Trenholm et al., 1999), while the stress indices are associated with turf response to abiotic stresses (Trenholm et al., 1999, 2000). Reflectance readings were taken within a time period from 1100 to 1300 HR under conditions of minimal cloud cover.

Because of differences in a number of parameters between trials, data are presented separately for each trial. Experimental design was a randomized complete block with four replications. Data were analyzed with SAS (SAS Institute, Cary, N.C.) for differences at the 0.05 probability level. Means separation was performed by the
Waller-Duncan $k$-ratio $t$-test at the 0.05 probability level.

For shade tolerance evaluations, st. augustinegrass cultivar Floratam and the experimental genotype 1997-6 were established in 15.2-cm-diameter plastic pots in a glasshouse at the University of Florida Turfgrass Research Envirotron in Gainesville. Sixteen pots of each cultivar were established on 20 Dec. 2000. Media and Si incorporation were as described above. Grasses were allowed to establish until 13 Feb 2001, when shade treatments were initiated. Half of the pots were placed under a $1-\mathrm{m}^{3}\left(35.3 \mathrm{ft}^{3}\right)$ shade structure covered with $50 \%$ shadecloth on top and all sides, while remaining pots were left in full sunlight. In the second trial, the shade level was increased to $70 \%$. The first trial of this study was terminated on 29 May 2001. The experiment was repeated from 10 June 2001 until 17 Sept. 2001. Irrigation was provided as needed to maintain evapotranspiration (ET). Fertilizer was applied as a modified Beckman's solution monthly to supply $12.206 \mathrm{~kg} \cdot \mathrm{ha}^{-1}$ nitrogen with each application. Grasses were mowed with hand clippers to a height of 6.35 cm every other week.

Visual turf quality, color, and density were recorded as described above. Reflectance measurements were also taken as described previously. Leaf blade measurements were made by selecting three blades per pot at random and measuring length and width. Terminal harvests provided dry weights of both roots and shoots.

Experimental design was a nested design, with experimental units nested within shade levels. There were four replications. Data were analyzed with SAS for differences at the 0.05 probability level. Means separation was performed by the Waller-Duncan $k$-ratio $t$-test at the 0.05 probability level. Because of differences in a number of parameters between trials, data are presented separately for each trial.

\section{Results and discussion}

Drought Tolerance. By month 3 of drought treatments, there were no differences in visual parameters between grasses when weekly visual scores were averaged over the month (Table 2). Leaf firing and density were greater by $13 \%$ and $23.5 \%$, respectively, in Si-amended pots. 'FHSA-115' had better density scores when treated with 
Table 2. Visual quality scores of two st. augustinegrass cultivars ('FX-10' and 'FHSA-115') with or without silicon ( $\mathrm{Si}$ ) for the last month of the drydown in trial 1. Means are averaged from weekly ratings. Visual scores are based on a scale from 1 to 9 , where $1=$ dead grass and $9=$ best quality.

\begin{tabular}{lccccc}
\hline Treatment & Quality & Color & Density & $\begin{array}{c}\text { Leaf } \\
\text { firing } \\
(\%)\end{array}$ & $\begin{array}{c}\text { Leaf } \\
\text { folding } \\
(\%)\end{array}$ \\
\hline FX-10 + Si & 3.7 & 4.5 & 3.9 & 75.0 & 63.6 \\
FX-10 - Si & 4.0 & 4.8 & 4.3 & 60.6 & 50.0 \\
FHSA-115 + Si & 4.0 & 4.8 & 4.5 & 60.0 & 66.3 \\
FHSA-115-Si & 2.8 & 4.0 & 2.6 & 58.8 & 67.4 \\
ANOVA & & & & & \\
$\quad$ Grass $(G)$ & NS & NS & NS & NS & NS \\
Silicon $(\mathrm{Si})$ & NS & NS & $*$ & $*$ & NS \\
G $\times$ Si & NS & NS & $*$ & NS & NS \\
CV $(\%)^{z}$ & 22 & 13 & 21 & 13 & 18 \\
\hline
\end{tabular}

${ }^{\mathrm{z}} \mathrm{ANOVA}=$ analysis of variance; $\mathrm{CV}=$ coefficient of variation

ss, ${ }^{*}$ Nonsignificant or significant at $P \leq 0.05$.
Table 3. Visual quality scores of two st. augustinegrass cultivars ('FX-10' and 'FHSA-115') with or without silicon ( $\mathrm{Si}$ ) for the drydown in trial 2. Means are averaged from weekly ratings. Visual scores are based on a scale from 1 to 9 , where 1 = dead grass and 9 = best quality.

\begin{tabular}{lccccc}
\hline Treatment & Quality & Color & Density & $\begin{array}{c}\text { Leaf } \\
\text { firing } \\
(\%)\end{array}$ & $\begin{array}{c}\text { Leaf } \\
\text { folding } \\
(\%)\end{array}$ \\
\hline FX-10 + Si & 4.3 & 4.9 & 5.3 & 15.0 & 69.9 \\
FX-10 - Si & 3.3 & 3.9 & 4.7 & 30.6 & 90.4 \\
FHSA115 + Si & 4.3 & 5.2 & 4.9 & 5.0 & 71.9 \\
FHSA115 - Si & 3.9 & 4.9 & 4.8 & 5.0 & 65.0 \\
ANOVA $^{z}$ & & & & & \\
$\quad$ Grass $(\mathrm{G})$ & $\mathrm{NS}$ & $*$ & $\mathrm{NS}$ & $*$ & $\mathrm{NS}$ \\
$\mathrm{Silicon}(\mathrm{Si})$ & $*$ & $*$ & $*$ & $\mathrm{NS}$ & $\mathrm{NS}$ \\
$\mathrm{G} \times \mathrm{Si}$ & $\mathrm{NS}$ & $\mathrm{NS}$ & $\mathrm{NS}$ & $\mathrm{NS}$ & $*$ \\
$\mathrm{CV}(\%)^{\mathrm{z}}$ & 15 & 11 & 6 & 100 & 16 \\
\hline
\end{tabular}

${ }^{\mathrm{z}} \mathrm{ANOVA}=$ analysis of variance; $\mathrm{CV}=$ coefficient of variation.

Ns, ${ }^{*}$ Nonsignificant or significant at $P \leq 0.05$
Si, while 'FX-10' did not have any difference in density due to treatment.

In trial 2, when drought stress was more severe, 'FX-10' again had greater leaf firing although 'FHSA115' retained better color (Table 3). Quality, color, and density were enhanced in both cultivars amended with $\mathrm{Si}$ over controls by $19 \%, 13.6 \%$, and $8.5 \%$, respectively. Under these test conditions, visual scores were all below what would be considered acceptable for turfgrass use. However, this demonstrates that Si may improve these turfgrass qualitative factors under extreme drought stress. By the end of trial 2, 'FX-10' had greater survival rates than 'FHSA-115', with no difference in survival of either grass due to Si treatment (data not shown).

There were differences in light assimilation due to grass through the visible range wavelengths as evidenced by multispectral reflectance (Table 4). At all measured wavelengths in the visible range, 'FHSA-115' had significantly better values (lower reflectance values) than 'FX-10'. Values for growth indices NDVI and IR/R and stress indices 1 and 2 also showed better performance for 'FHSA-115'. These measurements are correlated with overall turfgrass performance (Trenholm et al., 1999) and can be reliably used to determine stress in turfgrass (Trenholm et al., $2000)$. At $550 \mathrm{~nm}$, non-treated grasses had better light assimilation than those treated with Si. This reduction could be due to $\mathrm{Si}$ crystal deposition in the mesophyll cells, which may obstruct chloroplasts in assimilating light. This is similar to work reported by Trenholm et al. (2001), who found lower reflectance in control plots vs.

Table 4. Multispectral reflectance scores of two st. augustinegrass cultivars ('FX10 ' and 'FHSA-115') with or without silicon ( $\mathrm{Si}$ ) during drydown in trial 1 . Means are averaged from weekly measurements. Optimal reflectance scores are in bold.

\begin{tabular}{|c|c|c|c|c|c|c|c|c|}
\hline \multirow[b]{2}{*}{ Treatment } & \multicolumn{4}{|c|}{$\mathrm{nm}$} & \multicolumn{4}{|c|}{ Indices $^{\mathrm{z}}$} \\
\hline & $450^{y}$ & 550 & 660 & 694 & NDVI & LAI & Stress 1 & Stress2 \\
\hline $\mathrm{FX}-10+\mathrm{Si}$ & 10.8 & 15.1 & 14.8 & 15.0 & 0.57 & 3.7 & 0.50 & 0.45 \\
\hline $\mathrm{FX}-10-\mathrm{Si}$ & 10.1 & 14.2 & 13.6 & 13.7 & 0.56 & 3.6 & 0.48 & 0.44 \\
\hline FHSAII $+\mathrm{Si}$ & 9.5 & 13.5 & 12.3 & 12.6 & 0.61 & 4.2 & 0.48 & 0.43 \\
\hline FHSA1 $15-S i$ & 9.0 & 12.5 & 11.8 & 12.4 & 0.62 & 4.3 & 0.45 & 0.40 \\
\hline \multicolumn{9}{|l|}{ ANOVA $^{y}$} \\
\hline Grass (G) & ** & $* * *$ & $* * *$ & ** & $* * *$ & $* * *$ & NS & * \\
\hline Silicon $(S i)$ & NS & * * & NS & NS & NS & NS & NS & NS \\
\hline $\mathrm{G} \times \mathrm{Si}$ & NS & NS & NS & NS & NS & NS & NS & NS \\
\hline $\mathrm{CV}^{\mathrm{y}}(\%)$ & 6 & 4 & 6 & 7 & 4 & 7 & 5 & 5 \\
\hline
\end{tabular}

${ }^{2} \mathrm{NDVI}=\mathrm{R} 930-\mathrm{R} 660 / \mathrm{R} 930+\mathrm{R} 660 ; \mathrm{LAI}=\mathrm{R} 930 / \mathrm{R} 660 ;$ Stress1 index $=\mathrm{R} 710 / \mathrm{R} 760 ;$ Stress2 index $=$ $\mathrm{R} 710 / \mathrm{R} 810$; where R660, R710, R760, R810, and R930 are reflectance at $660,710,760,810$, and $930 \mathrm{~nm}$, respectively. Reflectance measurements were collected with a hand-held multispectral radiometer fitted with filter wavelengths.

"ANOVA $=$ analysis of variance $\mathrm{CV}=$ coefficient of variation

Ns, ***,**,*Nonsignificant or significant at $P \leq 0.001,0.01$, or 0.05 , respectively.

those receiving a high rate of potassium silicate as a foliar spray.

There were no differences in root or shoot growth in trial 1 . Trenholm et al. (2001) likewise found no enhancement of shoot growth in response to Si treatment in seashore paspalum. However, Brecht (2002) demonstrated a 17 to $34 \%$ increase in prostrate growth of 'Floratam' infected by gray leaf spot when amended with calcium silicate under field conditions.

SHADE STRESS. In both trials 1 and 2, 1997-6 had consistently higher quality scores than 'Floratam' (Tables 5 and 6) in both shaded and non-shaded conditions. 'Floratam' is generally considered to have poor shade tolerance among st. augustinegrass cultivars.

There were no differences in visual scores due to Si treatment in either grass. Scores for both grasses were consistently higher under full sunlight than in shade.
Amount of light reflected throughout the visible range wavelengths did not differ in response to $S i$ treatment in 'Floratam' (Table 7). Where differences existed due to shade, optimal responses occurred in shade treatments. Similar results were found in trial 2 (data not shown), even though the shade level had been increased to 70\%. 1997-6 had better reflectance values without Si under both shade and non-shaded conditions. As seen in the drought component of this work, $\mathrm{Si}$ appears to reduce light assimilation.

\section{Conclusions}

Pre-planting incorporation of Si into the substrate increased some visual ratings under severe drought conditions, with little improvement seen under mild drought conditions. Silicon did not provide any benefit to either grass under shade in this research. Future field research may 
Table 5. Visual quality scores of two st. augustinegrass cultivars ('Floratam', 1997-6) in trial 1 under shade or full sun and with or without silicon (Si). Means are averaged from weekly ratings. Visual scores based on a scale from 1 to 9 , where $1=$ dead grass and 9 = best quality.

\begin{tabular}{lccccc}
\hline Grass & Silicon & Shade & Quality & Color & Density \\
\hline Floratam & $+^{z}$ & + & 5.8 & 6.4 & 6.3 \\
& + & - & 5.8 & 6.5 & 6.7 \\
& - & + & 5.8 & 6.6 & 6.3 \\
& - & - & 5.9 & 6.5 & 6.6 \\
ANOVAy & & & & & \\
Si & & & $\mathrm{NS}^{\mathrm{x}}$ & $\mathrm{NS}$ & $\mathrm{NS}$ \\
Shade (Sh) & & & $* * *$ & $* * *$ & $* * *$ \\
Si $\times$ Sh & & & $\mathrm{NS}$ & $\mathrm{NS}$ & $\mathrm{NS}$ \\
CV (\%) & & & 9 & 4 & 6 \\
1997-6 & + & + & 6.2 & 7.2 & 6.7 \\
& + & - & 6.5 & 7.2 & 7.2 \\
& - & + & 6.2 & 7.4 & 6.8 \\
ANOVA & - & - & 6.2 & 6.9 & 7.1 \\
Si & & & & & \\
Shade (Sh) & & & $\mathrm{NS}$ & $\mathrm{NS}$ & $\mathrm{NS}$ \\
Si $\times$ Sh & & & $* * *$ & $*$ & $* * *$ \\
CV (\%) & & & 9 & $*$ & $*$ \\
\hline
\end{tabular}

${ }^{2}+=$ with treatment $;-=$ minus treatment.

yANOVA = analysis of variance; $\mathrm{CV}=$ coefficient of variation

Ns, ${ }^{* * *},{ }^{*}$ Nonsignificant or significant at $P \leq 0.001$ or 0.05 , respectively.
Table 6. Visual quality scores of two st. augustinegrass cultivars ('Floratam', 1997-6) in trial 2 under shade or full sun and with or without silicon ( $\mathrm{Si})$. Means are averaged from weekly ratings. Visual scores based on a scale from 1 to 9 , where $1=$ dead grass and 9 = best quality.

\begin{tabular}{lccccc}
\hline Grass & Silicon & Shade & Quality & Color & Density \\
\hline Floratam & + & $+^{z}$ & 3.0 & 5.5 & 3.5 \\
& + & - & 5.8 & 6.4 & 6.4 \\
& - & + & 2.9 & 5.3 & 3.1 \\
& - & - & 5.7 & 6.3 & 6.5 \\
ANOVAy & & & & & \\
Si & & & NS & NS & NS \\
Shade (Sh) & & & $* * *$ & $* *$ & $* * *$ \\
Si $\times$ Sh & & & NS & NS & NS \\
CV (\%) & & & 9 & 4 & 6 \\
1997-6 & + & + & 3.5 & 6.7 & 5.8 \\
& + & - & 6.4 & 7.0 & 7.3 \\
& - & + & 3.1 & 6.3 & 4.7 \\
& - & - & 6.5 & 7.2 & 7.8 \\
ANOVA & & & & & \\
Si & & & NS & NS & NS \\
Shade (Sh) & & & $* * *$ & $*$ & $* * *$ \\
Si $\times$ Sh & & & $*$ & $*$ & $*$ \\
CV (\%) & & & 9 & 3 & 9 \\
\hline
\end{tabular}

${ }^{z_{+}}=$with treatment $;-=$minus treatment

yANOVA $=$ analysis of variance; $\mathrm{CV}=$ coefficient of variation

Ns, ${ }^{* * *},{ }^{* *},{ }^{*}$ Nonsignificant or significant at $P \leq 0.001,0.01$, or 0.05 , respectively.

Table 7. Multispectral reflectance scores of two st. augustinegrass cultivars ('Floratam', 1997-6) in trial 2 under shade or full sun and with or without silicon (Si). Means are averaged from weekly measurements. Optimal reflectance scores are in bold.

\begin{tabular}{|c|c|c|c|c|c|c|c|c|c|c|}
\hline \multirow[b]{2}{*}{ Grass } & \multicolumn{2}{|c|}{ Treatment } & \multicolumn{4}{|c|}{$\mathrm{nm}$} & \multicolumn{4}{|c|}{ Indices $^{\mathrm{z}}$} \\
\hline & Silicon & $\overline{\text { Shade }}$ & 450 & 550 & 660 & 694 & NDVI & LAI & Stress 1 & Stress 2 \\
\hline \multirow[t]{4}{*}{ Floratam } & $+^{y}$ & + & 3.6 & 8.2 & 3.8 & 4.4 & 0.81 & 10.5 & 0.27 & 0.25 \\
\hline & + & - & 8.4 & 14.3 & 9.4 & 11.6 & 0.67 & 5.1 & 0.43 & 0.41 \\
\hline & - & + & 4.4 & 9.8 & 4.6 & 5.8 & 0.82 & 10.3 & 0.25 & 0.24 \\
\hline & - & - & 13.4 & 31.3 & 22.4 & 23.2 & 0.69 & 5.5 & 0.35 & 0.31 \\
\hline \multicolumn{11}{|l|}{ ANOVA $^{x}$} \\
\hline $\mathrm{Si}$ & & & $\mathrm{NS}^{\mathrm{w}}$ & NS & NS & NS & NS & NS & NS & NS \\
\hline Shade & & & * & NS & NS & NS & ** & ** & * & NS \\
\hline $\mathrm{Si} \times \mathrm{Sh}$ & & & NS & NS & NS & NS & NS & NS & NS & NS \\
\hline $\mathrm{CV}(\%)^{\mathrm{v}}$ & & & 80 & 74 & 75 & 60 & 5 & 23 & 22 & 27 \\
\hline \multirow[t]{4}{*}{$1997-6$} & + & + & 4.9 & 10.8 & 4.4 & 4.9 & 0.80 & 9.8 & 0.28 & 0.32 \\
\hline & + & - & 14.9 & 36.2 & 24.1 & 28.2 & 0.75 & 7.8 & 0.29 & 0.24 \\
\hline & - & + & 3.2 & 6.4 & 3.2 & 4.0 & 0.84 & 12.5 & 0.23 & 0.22 \\
\hline & - & - & 5.8 & 10.2 & 5.9 & 7.0 & 0.77 & 7.8 & 0.33 & 0.30 \\
\hline \multicolumn{11}{|l|}{ ANOVA } \\
\hline $\mathrm{Si}$ & & & * & ** & * & * & NS & NS & NS & NS \\
\hline Shade & & & $*$ & * & ** & ** & NS & NS & NS & NS \\
\hline $\mathrm{Si} \times \mathrm{Sh}$ & & & NS & * & * & * & NS & NS & NS & NS \\
\hline CV (\%) & & & 54 & 53 & 69 & 64 & 8 & 39 & 17 & 30 \\
\hline
\end{tabular}

${ }^{2} \mathrm{NDVI}=\mathrm{R} 930-\mathrm{R} 660 / \mathrm{R} 930+\mathrm{R} 660 ; \mathrm{LAI}=\mathrm{R} 930 / \mathrm{R} 660 ;$ Stress1 index $=\mathrm{R} 710 / \mathrm{R} 760 ;$ Stress2 index $=$ R710/R810; where R660, R710, R760, R810, and R930 are reflectance at $660,710,760,810$, and $930 \mathrm{~nm}$, respectively. Reflectance measurements were collected with a hand-held multispectral radiometer fitted with filter wavelengths.

$y_{+}=$with treatment $;-=$minus treatment.

${ }^{\mathrm{A}} \mathrm{ANOVA}=$ analysis of variance; $\mathrm{CV}=$ coefficient of variation

${ }^{N s, * * *}$ Nonsignificant or significant at $P \leq 0.01$ or 0.05 , respectively.

clarify the extent to which Si might be used to improve drought or shade tolerance.

\section{Literature cited}

Belanger, R.R., P.A. Bowen, D.L. Ehret, and J.G. Menzes. 1995. Soluble silicon: Its role in crop and disease management of greenhouse crops. Plant Dis. 79:329-336.

Brecht, M.O., Datnoff, L.E., Kucharek, T.A., and Nagata, R.T. 2004. Influence of silicon and chlorothalonil on the suppression of gray leaf spot and increase plant growth in st. augustinegrass. Plant Dis. 88:338-344.
Datnoff, L. E,. G.H. Snyder, and G.H. Korndorfer. 2001. Silicon in agriculture.Elsevier Sci., Amsterdam, The Netherlands.

Epstein, E. 1994. The anomaly of silicon in plant biology. Proc. National Acad. Sci. 91:11-17.

Epstein, E. 1999. Silicon. Annu. Rev.Plant Physiol. Plant Mol. Biol. 50:641-664.

Gussack, E., M. Petrovic, and F. Rossi. 1998. Silicon: The universal contaminant. Cornell Univ. Turfgrass Times 9:9-11.

North Carolina State University. 1997. Effect of soluble silica on brown patch and dollar spot of creeping bentgrass. North Carolina Turfgrass Aug/Sept:34-36.

Savant, N.K., G.H. Korndorfer, L.E. Datnoff, and G.H. Snyder. 1999. Silicon nutrition and sugarcane production: A review. J. Plant Nutr. 22(12):1853-1903.

Savant, N.K., G.H. Snyder, and L.E. Datnoff. 1997. Silicon management and sustainable rice production. Adv. Agron. 58:151-199.

Trenholm, L.E., R.N. Carrow, and R.R. Duncan. 1999. Relationship of multispectral radiometry to qualitative data in turfgrass research. Crop Sci. 39:763-769.

Trenholm, L.E., M.J. Schlossberg, G. Lee, W. Parks, and S.A. Geer. 2000. An evaluation of multi-spectral responses on selected turfgrass species. Intl. J. Remote Sensing 21:709-721.

Trenholm, L.E., R.R. Duncan, R.N. Carrow, and G.H. Snyder. 2001. Influence of silica on growth, quality, and wear tolerance of seashore paspalum. J. Plant Nutr. 24:245-259.

Wang, S.Y. and G.J. Galletta. 1998. Foliar application of potassium silicate induces metabolic changes in strawberry plants. J. Plant Nutr. 21:157-167. 